\title{
Smac Mimetic LCL161
}

National Cancer Institute

\section{Source}

National Cancer Institute. Smac Mimetic LCL161. NCI Thesaurus. Code C91079.

An orally bioavailable second mitochondrial-derived activator of caspases (SMAC) mimetic and inhibitor of IAP (Inhibitor of Apoptosis Protein) family of proteins, with potential antineoplastic activity. SMAC mimetic LCL161 binds to IAPs, such as X chromosome-linked IAP (XIAP) and cellular IAPs 1 and 2. Since IAPs shield cancer cells from the apoptosis process, this agent may restore and promote the induction of apoptosis through apoptotic signaling pathways in cancer cells. IAPs are overexpressed by many cancer cell types and suppress apoptosis by binding and inhibiting active caspases-3,-7 and -9, which play essential roles in apoptosis (programmed cell death), necrosis and inflammation. 